\title{
The complete mitochondrial genome of a gecko and the phylogenetic position of the Middle Eastern Teratoscincus keyserlingii
}

J. Robert Macey ${ }^{1,2}$, Jonathan J. Fong ${ }^{1,2}$, Jennifer V. Kuehl ${ }^{1}$, Soheila Shafiei ${ }^{3}$, Natalia B. Ananjeva $^{4}$, Theodore J. Papenfuss ${ }^{2}$, and Jeffrey L. Boore ${ }^{1,5}$

${ }^{1}$ Department of Evolutionary Genomics, DOE Joint Genome Institute and Lawrence Berkeley National Laboratory, 2800 Mitchell Drive, Walnut Creek, CA 94598

${ }^{2}$ Museum of Vertebrate Zoology, University of California, Berkeley, CA 94720

${ }^{3}$ Department of Biology, Shahid Bahonar University, P.O. Box 76169-133, Kerman, Iran

${ }^{4}$ Zoological Institute, Russian Academy of Sciences, St. Petersburg, 199034, Russia

${ }^{5}$ Department of Integrative Biology, 3060 Valley Life Science Building, University of California, Berkeley, CA 94720

Reptilia; Squamata; Gekkota; Gekkonidae; mitochondrial DNA; genomics; Phylogenetics; biogeography; Middle East

Running head: Middle Eastern Gecko Mt-Genome

Correspondence to: J. Robert Macey, Department of Evolutionary Genomics, DOE Joint Genome Institute and Lawrence Berkeley National Laboratory, 2800 Mitchell Drive, Walnut Creek, CA 94598-1631; Phone: 925-296-5621; FAX: 925-296-5666; e-mail: jrmacey@lbl.gov 


\section{Introduction}

Sqamate reptiles are traditionally divided into six groups: Iguania, Anguimorpha, Scincomorpha, Gekkota (these four are lizards), Serpentes (snakes), and Amphisbaenia (the socalled worm lizards). Currently there are complete mitochondrial genomes from two representatives of the Iguania (Janke et al., 2001; Kumazawa, 2004), three from the Anguimorpha (Kumazawa, 2004; Kumazawa and Endo, 2004), two from the Scincomorpha (Kumazawa and Nishida, 1999; Kumazawa, 2004), two from Serpentes (Kumazawa et al., 1998; Kumazawa, 2004) and 12 from Amphisbaenia (Macey et al., 2004). The only traditional group of Squamata from which a complete mitochondrial genome has not been sequenced is the Gekkota.

Here we report the complete mitochondrial genome of Teratoscincus keyserlingii, a Middle Eastern representative of the Gekkota. The gekkonid lizard genus Teratoscincus is distributed throughout the deserts of central and southwest Asia as shown in figure 1, with five species currently recognized (Macey et al. 1997a, 1999b). Included in this figure are the positions of mountain ranges discussed in the text; see also figure 1 in Macey et al. (1999b). Two species, T. bedriagai and T. microlepis, are restricted to Southwest Asia south of the Kopet Dagh and Hindu Kush in Iran, Afghanistan, and Pakistan (Anderson, 1999). Two species are found in the deserts of western China and Mongolia, with T. przewalskii occurring in the Taklimakan and lowland Gobi deserts, and T. roborowskii restricted to the Turpan Depression. The fifth species, T. scincus, is sometimes considered to be restricted to the Caspian Basin in Kazakhstan, Kyrgyzistan, Tadjikistan, Turkmenistan and Uzbekistan. Alternatively, Teratoscincus populations in Southwest Asia, primarily on the Iranian Plateau, situated directly north of the 
Arabian Plate, are sometimes considered to be a subspecies of T. scincus or, otherwise, to constitute a sixth species, T. keyserlingii.

Macey et al. (1999b) assessed the phylogenetic relationships of four Teratoscincus species with mitochondrial DNA sequences from a 1800 base-pair segment spanning from nadl to coxl. Phylogenetic analysis places $T$. microlepis in a basal position to a clade containing $T$. scincus, T. przewalskii and T. roborowskii, with the later two as sister taxa. This phylogenetic arrangement suggests that tectonic plate movements in Southwest Asia and western China due to the Indian and Arabian collisions caused speciation among Teratoscincus species. No molecular phylogenetic study has included the putative species T. keyserlingii.

\section{Materials and methods}

\subsection{Specimen Information}

The sample of T. keyserlingii from which DNA was extracted is deposited in the Museum of Vertebrate Zoology, University of California at Berkeley as MVZ 243455. The collection locality of this specimen is elevation 740 feet, $30^{\circ} 26.741^{\prime} \mathrm{N} 57^{\circ} 49.967^{\prime} \mathrm{E}$, east side of Shahdad, Kerman Province, Iran. The complete mitochondrial genome sequence from this specimen of $T$. keyserlingii is deposited in GenBank as accession number AY753545.

This sample of $T$. keyserlingii is selected because it is close to the type locality of $T$. keyserlingii in the Lut Desert of eastern Iran. The original type locality is given as Seri-Tschah, eastern Iran by Strauch (1863) but is most likely Sar-I-Chah, 32 $16^{\prime} \mathrm{N} 58^{\circ} 52^{\prime} \mathrm{E}$, Khorasan (Blanford, 1876; also see Anderson, 1999). 


\subsection{Laboratory Protocols}

Genomic DNA was extracted from liver using the Qiagen QIAamp tissue kit. Amplification of the mtDNA was conducted using rTth long PCR enzyme (Applied Biosystems) with a beginning denaturation at $94^{\circ} \mathrm{C}$ for $45 \mathrm{sec}$, then followed by 37 cycles of a denaturation at $94^{\circ} \mathrm{C}$ for $15 \mathrm{sec}$, annealing at $50^{\circ} \mathrm{C}$ for $20 \mathrm{sec}$, and extension at $68^{\circ} \mathrm{C}$ for $9 \mathrm{~min}$, with a final extension at $72^{\circ} \mathrm{C}$ for 12 min after the last cycle. Negative controls were run on all amplifications to check for contamination. Initial amplifications were conducted using primers described in Macey et al. (1997b, 1999b). Perfectly matching primers were then constructed based on the DNA sequence of this fragment to complete the amplification of each mtDNA in two additional long PCR fragments.

Amplification products were sheared randomly into fragments of approximately $1.5 \mathrm{~kb}$ by repeated passage through a narrow aperture using a Hydroshear device (GeneMachines). After end-repair, the sheared DNA was gel purified and ligated into pUC18 vector to construct a library of random fragments, then transformed into bacterial cells. Automated colony pickers introduced single clones into bacterial broth in 384-well format. These plasmid clones were processed robotically through rolling circle amplification (Dean et al., 2001; Hawkins et al., 2002), sequencing reactions, and reaction clean up using SPRI (Elkin et al., 2002). Sequences

were determined using ABI3730xl or MegaBace 4000 DNA sequencers, then assembled to form a deep, contiguous sequence using Phrap (Green, 1996) or Sequencher 3.0 (Gene Codes Co., Ann Arbor, MI).

\subsection{Phylogenetic Analysis}


The phylogenetic analysis is based on nucleotide sequences for the same region of the mitochondrial genome from nadl to coxl as presented in Macey et al. (1999b). DNA sequences for protein- and tRNA-encoding genes were aligned manually as in Macey et al. (1999b). Positions encoding proteins were translated to amino acids using MacClade 4.03 (Maddison and Maddison, 2001) for confirmation of alignment. Alignments of sequences encoding tRNAs were constructed based on secondary structural models (Kumazawa and Nishida, 1993; Macey and Verma, 1997). Unalignable regions totaling 82 positions were excluded from phylogenetic analyses as in Macey et al. (1999b). These positions are situated at the end of nadl, in $\mathrm{O}_{\mathrm{L}}$, and the D- and T-loops of trnW and -trnC (see figure 2 in Macey et al., 1999b).

The region analyzed in Macey et al. (1999b) from nadl to coxl corresponds to positions $3558-5330$ of the complete mitochondrial genome of T. keyserlingii and has a length of 1773 bases. To align this new sequence with the data of Macey et al. (1999b) a total of 42 gaps are introduced. These gaps are after the following positions on the complete mitochondrial genome of T. keyserlingii with the number of gaps introduced in parenthesis if more than one: 3668 (7), 3797, 3828, 3860, 3864, 3881, 4927 (3), 4942 (7), 4976, 4980, 4993 (6), 5010, 5049, 5136 (2), $5141,5156(2), 5163,5181,5230,5243$, and 5281. Sequence divergences based on this alignment are reported as uncorrected pairwise divergences.

Phylogenetic trees were inferred by parsimony using PAUP* beta version $4.0 \mathrm{~b} 8$ (Swofford, 2001) with the branch and bound search option, which guarantees an exact solution. Bootstrap resampling (Felsenstein, 1985a) was applied to assess support for individual nodes using 1000 branch and bound replicates. Decay indices (= "branch support" of Bremer, 1994) were calculated for all internal branches using branch and bound searches that retained suboptimal nodes. 
In order to test specific, alternative phylogenetic hypotheses, we first built incompletely resolved constraint trees using MacClade (Maddison and Maddison, 2001). These were provided as input into PAUP* (Swofford, 2001) for branch and bound searches to determine the most parsimonious tree compatible with each alternative hypothesis. We then compared these to the unconstrained most parsimonious tree using Wilcoxon signed-ranks tests (Templeton, 1983). This test determines whether the most parsimonious tree is significantly shorter than each alternative or whether their differences in length are statistically indistinguishable. Wilcoxon signed-ranks tests were conducted as two-tailed tests (Felsenstein, 1985b) using PAUP* (Swofford, 2001), which incorporates a correction for tied ranks.

\section{Results}

\subsection{Mitochondrial genomic structure}

The complete mitochondrial genome of $T$. keyserlingii is 17,199 base pairs in length. This genome contains the same 37 genes common among animals and they are ordered as is most commonly found for vertebrates (Boore, 1999). The two replication origins are located in the typical vertebrate locations as well. This order as in T. keyserlingii is trnF, $r r n S$, trnV, $r r n L$, $\operatorname{trnL}(U U R), n a d 1, \operatorname{trn} I,-Q, M, \operatorname{nad} 2, \operatorname{trn} W,-A,-N,-C, \mathrm{O}_{\mathrm{L}},-\operatorname{trn} Y$, coxl, $-\operatorname{trn} S(U C N), D, \operatorname{cox} 2$, trnK, atp8, atp6, cox3, trnG, nad3, trnR, nad4L, nad4, trnH, S (AGY), L (CUN), nad5, -nad6, -trnE, cob, trnT, -trnP, and Control Region. The noncoding region typically observed between -trnP and $\operatorname{trn} F$, presumed to be the Control Region, is 2,117 base pairs in length. This region has seven near identical repeats of 48 nucleotides adjacent to - $\operatorname{trn} P$.

Some squamate reptiles are known to contain atypical vertebrate mitochondrial genomes. Three main observations have been made: (1) gene rearrangements, (2) duplicated genes, and (3) 
duplicated Control Regions. Gene rearrangements are known in amphisbaenian reptiles (Macey et al., 1994), Acrodonta including the lizard families Agamidae and Chamaeleonidae (Macey et al. 1997b, c, 2000), the snake family Leptotyphlopidae (Kumazawa and Nishida, 1995;

Kumazawa and Endo, 2004), "advanced snakes" (Kumazawa and Nishida, 1995; Kumazawa et al., 1998), and the lizard family Varanidae (Kumazawa and Endo, 2004). Duplicated genes are known in Cnemidophorus lizards in the family Teiidae (Moritz and Brown, 1986, 1987), Heternotia geckoes in the family Gekkonidae (Moritz, 1991), the amphisbaenian species Bipes biporus (Macey et al. 1998, 2004), and the lizard family Cordylidae (Kumazawa, 2004).

Duplicated Control Region sequences are independently (see Townsend et al., 2004) associated with gene rearrangements in "advanced snakes" (Kumazawa and Nishida, 1995; Kumazawa et al., 1998), and the lizard family Varanidae (Kumazawa and Endo, 2004). In addition, the loss of the stem-loop structure implicated as the light-strand origin for replication from it's typical location between $-\operatorname{trnN}$ and $-C$ is associated with the majority of gene rearrangements among vertebrates and many squamate reptiles (reviewed in Boore et al., 2005; Macey et al. 1997b,c, 2000, 2004). All of these features are observed as the typical vertebrate state in T. keyserlingii, and not as just outlined for some exceptions among squamate reptiles.

\subsection{Phylogenetic relationships}

Phylogenetic analysis of the 1733 aligned positions (381 informative) produces a single most parsimonious tree (Fig. 2). All relationships are well supported by a bootstrap value of $100 \%$. The monophyly of Teratoscincus receives further support from a decay index of 64 . The monophyly of $T$. scincus, $T$. keyserlingii, $T$. przewalskii, and $T$. roborowskii, to the exclusion of T. microlepis is supported by a decay index of 35. Teratoscincus scincus and T. keyserlingii are 
sister taxa (decay index 20), and T. przewalskii and T. roborowskii are sister taxa (decay index 24). The shortest alternative tree that does not unite T. scincus and T. keyserlingii requires 20 extra steps and is rejected by the Wilcoxon-signed-ranks test (Felsenstein, 1985b; Templeton, $1983)$ in favor of the unconstrained shortest tree $(\mathrm{n}=45, \mathrm{Z}=3.0861, P<0.002)$.

The phylogenetic results provide an area cladogram for Teratoscincus (Fig. 2). The Chinease-Mongolian deserts (Taklimakan, Gobi and Turpan) are monophyletic and the Caspian Basin is sister to the Iranian Plateau. Collectively these regions are monophyletic to the exclusion of the Afghan-Pakistan deserts (Helmand Basin and Makran).

\section{Discussion}

\subsection{Sequence divergences and geologic history}

Four geologic events can be mapped onto the phylogenetic tree [Fig. 2, also see figure 5 in Macey et al. (1999b) for a tectonic map of central and southwest Asia]. The rise of the Hindu Kush of central Afghanistan has been previously hypothesized to be responsible for vicariant separation of T. microlepis from the ancestor of T. scincus, T. keyserlingii, T. przewalskii, and $T$. roborowskii (Macey et al., 1999b). The initial rise of the Hindu Kush is coupled with the Karakorum Range and are approximately 20 million years old (Le Fort, 1998; Searle, 1991). The Tien Shan separates T. scincus of the Caspian Basin and T. keyserlingii of the Iranian Plateau from T. przewalskii and T. roborowskii of western China and Mongolia, and is well dated at 10 MYBP (million years before present; Abdrakhmatov et al., 1996). The rise of the Kopet-Dagh along the Iran-Turkmen border is coupled with intense Miocene activity along the Red Sea rift causing deformation in the Iranian Plateau by the Arabian collision (Girdler, 1984). While uplift of the Kopet-Dagh was most intense in the Middle Pliocene 3-4 MYBP (Sborshchikov et al., 
1981), a conservative estimate of minimum age is at least 5 MYBP at the time of major activity along the Red Sea rift (Girdler, 1984), and may correspond to the separation of T. scincus and $T$. keyserlingii. The Kuruk Tagh separates T. przewalskii in the Tarim Basin and Gobi Desert from T. roborowskii endemic to the Turpan Depression, and is coupled with east-west fault movements at the Mio-Pliocene boundary 5 MYBP (Tapponnier and Molnar, 1979; Windley et al., 1990).

The region of mitochondrial DNA examined here spanning from nadl to coxl has been shown to evolve at a rate of $1.3 \%$ per million years (MY) for uncorrected pairwise comparisons (Macey et al., 1998a). This calibration has been shown to be robust across numerous amphibian and reptile taxa (reviewed in Weisrock et al., 2001). Using the four geologic events that separate Teratoscincus species independently to calculate divergence rates (Table 1), a close calibration is made using the Tien Shan and Kuruk Tagh events (1.18\% and 1.31\% per MY). The Kopet-Dagh is a little higher (1.7\%) and the Hindu Kush lower (0.82\%). The Kopet-Dagh may be older than 5 MYBP due to earlier movement along the Red Sea rift (Girdler, 1984), and mitochondrial DNA is known to begin to accumulating multiple substitutions at the same site beyond 10 million years (Moritz et al., 1987) suggesting that a linear relationship between sequence divergence and time may not be expected. Previous studies have not examined divergence rates of transversional changes across this region of the mitochondrial genome. Examination of transversional divergences across these four geologic barriers yields a remarkably similar rate of change per million years $(0.21-0.31 \%)$. Although our calculations are not exactly the same, there is good evidence that these sequences are evolving in a clock-like manner.

\subsection{Taxonomic considerations}


A large amount of comparative sequence data are available in the literature for the segment of mitochondrial DNA sequence examined here from nadl to coxl. The amount of sequence divergence observed across the Kopet-Dagh between T. scincus and T. keyserlingii is 8.5\%. This is larger than that typically observed between species pairs of amphibians and reptiles (Table 2). Because $T$. keyserlingii is completely allopatric, isolated for millions of years, and is highly divergent from T. scincus, we recommend specific status for this taxon. A complete synonymy for Iranian populations is presented in Anderson (1999), and the oldest name available is $T$. keyserlingii.

\section{Acknowledgements}

Karen Klitz prepared figure 1. This work is LBNL-56819 and was performed under the auspices of the U.S. Department of Energy, Office of Biological and Environmental Research, under contract No. DE-AC03-76SF00098 with the University of California, Lawrence Berkeley National Laboratory. 


\section{References}

Abdrakhmatov, K.Ye., Aldazhanov, S.A., Hager, B.H., Hamburger, M.W., Herring, T.A., Kalabaev, K.B., Makarov, V.I., Molnar, P., Panasyuk, S.V., Prilepin, M.T., Reilinger, R.E., Sadybakasov, I.S., Souter, B.J., Trapeznikov, Y.A., Tsurkov, V.Ye., Zubovich, A.V., 1996. Relatively recent construction of the Tien Shan inferred from GPS measurements of present-day crustal deformation rates. Nature 384, 450-453.

Anderson, S.C., 1999. The Lizards of Iran. Contr. to Herptol. 15, Soc. Study of Amph. and Rept., Oxford, Ohio. 442 pp.

Blanford, W.T., 1876. Eastern Persia. An Account of the Journeys of the Persian Boundary Commission, 1870-1872, vol. 2. The Zoology and Geology. Macmillan and Co., London, $516 \mathrm{pp}$.

Boore, J.L., 1999. Animal mitochondrial genomes. Nucleic Acids Res. 27, 1767-1780.

Boore, J. L., Macey, J.R., Medina, M., 2005. Sequencing and comparing whole mitochondrial genomes of animals. In: Zimmer, E.A., Roalson, E. (Eds.), Methods in Enzymology: Producing the Biochemical Data II. Elsevier, Amsterdam, (in press).

Bremer, K., 1994. Branch support and tree stability. Cladistics 10, 295-304.

Dean, F.B., Nelson, J.R., Giesler, T.L., Lasken, R.S., 2001. Rapid amplification of plasmid and phage DNA using Phi 29 DNA polymerase and multiply-primed rolling circle. Genome Res. 11, 1095-1099.

Elkin, C., Kapur, H., Smith, T., Humphries, D., Pollard, M., Hammon, N., Hawkins, T., 2002. Magnetic bead purification of labeled DNA fragments for high-throughput capillary electrophoresis sequencing. Biotechniques 32, 1296-1302.

Felsenstein, J., 1985a. Confidence limits on phylogenies: An approach using the bootstrap. Evol. 
39, 783-791.

Felsenstein, J., 1985b. Confidence limits on phylogenies with a molecular clock. Syst. Zool. 34, $152-161$.

Girdler, R.W., 1984. The evolution of the Gulf of Aden and Red Sea in space and time. DeepSea Research, part A, 31, 747-762.

Green, P., 1996. http://bozeman.mbt.washington.edu/phrap.docs/phrap.html.

Hawkins, T.L., Detter, J.C., Richardson, P.M., 2002. Whole genome amplification-applications and advances. Curr. Opin. Biotechnol. 13, 65-67.

Janke, A., Erpenbeck, D., Nilsson, M., Arnason, U., 2001. The mitochondrial genomes of the iguana (Iguana iguana) and the caiman (Caiman crocodylus): Implications for amniote phylogeny. Proc. R. Soc. Lond., B, Biol. Sci. 268, 623-631.

Kumazawa, Y., 2004. Mitochondrial DNA sequences of five squamates: Phylogenetic affiliation of snakes. DNA Res. 11, 137-144.

Kumazawa, Y., Endo, H., 2004. Mitochondrial genome of the Komodo Dragon: Efficient sequencing method with reptile-oriented primers and novel gene rearrangements. DNA Res. 11, 115-125.

Kumazawa, Y., Nishida, M., 1993. Sequence evolution of mitochondrial tRNA genes and deepbranch animal phylogenetics. J. Mol. Evol. 37, 380-398.

Kumazawa, Y., Nishida, M., 1995. Variations in mitochondrial tRNA gene organization of reptiles as phylogenetic markers. Mol. Biol. Evol. 12, 759-772.

Kumazawa, Y., Nishida, M., 1999. Complete mitochondrial DNA sequences of the green turtle and blue-tailed mole skink: statistical evidence for archosaurian affinity of turtles. Mol. Biol. Evol. 16, 784-792. 
Kumazawa, Y., Ota, H., Nishida, M., Ozawa, T., 1998. The complete nucleotide sequence of a snake (Dinodon semicarinatus) mitochondrial genome with two identical control regions. Genetics 150, 313-329.

Le Fort, P., 1998. Granites in the tectonic evolution of the Himalaya, Karakorum and southern Tibet. In: Shackleton, R.M., Dewey, J.F., Windley, B. F. (Eds.), Tectonic Evolution of the Himalayas and Tibet. Phil. Trans. R. Soc. Lond. A 326, 281-299.

Macey, J.R., Ananjeva, N.B., Wang, Y., Papenfuss, T.J., 1997a. A taxonomic reevaluation of the gekkonid lizard genus Teratoscincus in China. Rus. J. Herp. 4, 8-16.

Macey, J.R., Larson, A., Ananjeva, N.B., Fang, Z., Papenfuss, T.J., 1997b. Two novel gene orders and the role of light-strand replication in rearrangement of the vertebrate mitochondrial genome. Mol. Biol. Evol. 14, 91-104.

Macey, J. R., Larson, A., Ananjeva, N. B., Papenfuss, T. J., 1997c. Evolutionary shifts of three major structural features in the mitochondrial genome among iguanian lizards. J. Mol. Evol. 44, 660-674.

Macey, J.R., Schulte II, J.A., Ananjeva, N.B, Larson, A., Rastegar-Pouyani, N., Shammakov, S. M., Papenfuss, T.J., 1998a. Phylogenetic relationships among agamid lizards of the Laudakia caucasia species group: Testing hypotheses of biogeographic fragmentation and an area cladogram for the Iranian Plateau. Mol. Phylogenet. Evol. 10, 118-131.

Macey, J.R., Schulte II, J.A., Larson, A., Fang, Z., Wang, Y., Tuniyev, B.S., Papenfuss, T.J., 1998b. Phylogenetic relationships of toads in the Bufo bufo species group from the eastern escarpment of the Tibetan Plateau: A case of vicariance and dispersal. Mol. Phylogenet. Evol. 9, 80-87.

Macey, J.R., Strasburg, J.L., Brisson, J.A., Vredenburg, V.T., Jennings, M., Larson, A., 2001. 
Molecular phylogenetics of Western North American frogs of the Rana boylii species group. Mol. Phylogenet. Evol. 19, 131-143.

Macey, J.R., Schulte II, J.A., Larson, A., Tuniyev, B.S., Orlov, N., Papenfuss, T.J., 1999a. Molecular phylogenetics, tRNA evolution and historical biogeography in anguid lizards and related taxonomic families. Mol. Phylogenet. Evol. 12, 250-272.

Macey, J.R., Wang, Y., Ananjeva, N.B., Larson, A., Papenfuss, T.J., 1999b. Vicariant patterns of fragmentation among gekkonid lizards of the genus Teratoscincus produced by the Indian Collision: A molecular phylogenetic perspective and an area cladogram for Central Asia. Mol. Phylogenet. Evol. 12, 320-332.

Macey, J.R., Schulte II, J.A., Larson, A., Papenfuss, T.J., 1998. Tandem duplication via lightstrand synthesis may provide a precursor for mitochondrial genomic rearrangement. Mol. Biol. Evol. 15, 71-75.

Macey, J.R., Schulte II, J.A., Larson, A., 2000. Evolution and phylogenetic information content of mitochondrial genomic structural features illustrated with acrodont lizards. Syst. Biol. 49, 257-277.

Macey, J.R., Papenfuss, T.J., Kuehl, J.V., Fourcade, H.M., Boore, J.L. 2004. Phylogenetic Relationships Among Amphisbaenian Reptiles Based on Complete Mitochondrial Genomic Sequences. Mol. Phylogenet. Evol. 33, 22-31.

Macey, J.R., Verma, A., 1997. Homology in phylogenetic analysis: Alignment of transfer RNA genes and the phylogenetic position of snakes. Mol. Phylogenet. Evol. 7, 272-279.

Maddison, W.P., Maddison, D.R., 2001. MacClade, Analysis of Phylogeny and Character Evolution, Version 4.06. Sinauer, Sunderland, MA.

Moritz, C. 1991. Evolutionary dynamics of mitochondrial DNA duplications in parthenogenetic 
geckos, Heteronotia binoei. Genetics 129, 221-230.

Moritz, C., Brown, W.M., 1986. Tandem duplications of D-loop and ribosomal RNA sequences in lizard mitochondrial DNA. Science 233, 1425-1427.

Moritz, C., Brown, W.M., 1987. Tandem duplications in animal mitochondrial DNAs: variation in incidence and gene content among lizards. Proc. Natl. Acad. Sci. USA 84, 7183-7187.

Moritz, C., Dowling, T.E., Brown, W.M., 1987. Evolution of animal mitochondrial DNA: Relevance for population biology and systematics. Annu. Rev. Ecol. Syst. 18, 269-292.

Sborshchikov, I.M., Savostin, L.A., Zonenshan, L.P., 1981. Present plate tectonics between Turkey and Tibet. Tectonophysics 79, 45-73.

Searle, M.P., 1991. Geology and Tectonics of the Karakorum Mountains. John Wiley and Sons, New York, $358 \mathrm{p}$.

Strauch, A.A., 1863. Characteristik zweier neuen Eidechsen aus Persien. Bulletin de l'Académie Impériale des Sciences de St. Pétersbourg 6, 477-480.

Swofford, D. L., 2001. "PAUP* Phylogenetic Analysis Using Parsimony (*and Other Methods), Beta Version 4.0b10,” Sinauer, Sunderland, MA.

Szczerbak, N.N., Golubev, M.L., 1996. Gecko fauna of the USSR and contiguous regions. Contr. to Herptol. 13, Soc. Study of Amph. and Rept., Oxford, Ohio, 233 p.

Templeton, A.R., 1983. Phylogenetic inference from restriction endonuclease cleavage site maps with particular reference to the evolution of humans and the apes. Evol. 37, 221-244.

Tapponnier, P., Molnar, P., 1979. Active faulting and Cenozoic tectonics of the Tien Shan, Mongolia, and Baykal regions. J. Geophys. Res. 84, 3425-3459.

Townsend, T., Larson, A., Louis, E., Macey, J.R., 2004. A New Hypothesis of Squamate Evolutionary Relationships From Nuclear and Mitochondrial DNA Sequence Data. Syst. 
Biol. 53, 735-757.

Weisrock, D.W., Macey, J.R., Ugurtas, I.H., Larson, A., Papenfuss, T.J., 2001. Molecular phylogenetics and historical biogeography among salamandrids of the "true" salamander clade: Rapid branching of numerous highly divergent lineages with the rise of Anatolia in Mertensiella luschani. Mol. Phylogenet. Evol. 18, 434-448.

Windley, B.F., Allen, M.B., Zhang, C., Zhao, Z.-Y., Wang, G.-R., 1990. Paleozoic accretion and Cenozoic redeformation of the Chinese Tien Shan Range, Central Asia. Geology 18, 128131. 
Table 1

Sequence divergences across taxa and dated geologic events with rates per million years ${ }^{\mathrm{a}}$

\begin{tabular}{|c|c|c|c|c|c|c|c|}
\hline & 1 & 2 & 3 & 4 & 5 & 6 & 7 \\
\hline 1. Eublepharus & - & $35.52 \%$ & $31.02 \%$ & $30.83 \%$ & $31.36 \%$ & $30.30 \%$ & $30.59 \%$ \\
\hline 2. Gecko & $20.31 \%$ & - & $30.70 \%$ & $32.05 \%$ & $32.53 \%$ & $31.97 \%$ & $32.45 \%$ \\
\hline 3. T. microlepis & $18.01 \%$ & $16.20 \%$ & - & $15.97 \%$ & $16.79 \%$ & $15.91 \%$ & $16.56 \%$ \\
\hline 4. T. scincus & $17.26 \%$ & $16.93 \%$ & $5.17 \%$ & - & $8.52 \%$ & $11.12 \%$ & $11.59 \%$ \\
\hline 5. T. keyserlingii & $17.32 \%$ & $16.99 \%$ & $5.64 \%$ & $1.52 \%$ & - & $12.41 \%$ & $12.12 \%$ \\
\hline 6. T. przewalskii & $17.32 \%$ & $16.68 \%$ & $5.76 \%$ & $2.93 \%$ & $3.16 \%$ & - & $6.55 \%$ \\
\hline \multirow[t]{2}{*}{ 7. T. roborowskii } & $17.38 \%$ & $16.86 \%$ & $5.76 \%$ & $2.99 \%$ & $3.22 \%$ & $1.05 \%$ & - \\
\hline & & \multicolumn{2}{|l|}{ Sequence } & Rate & \multicolumn{2}{|c|}{ TV Sequence } & TV Rate \\
\hline Mtn. Range & Age & \multicolumn{2}{|l|}{ Divergence } & per MY & \multicolumn{2}{|c|}{ Divergence } & per MY \\
\hline Hindu Kush & $20 \mathrm{MY}$ & $16.31 \%$ & \multicolumn{2}{|c|}{$0.82 \%$} & \multicolumn{2}{|c|}{$5.58 \%$} & $0.28 \%$ \\
\hline Tien Shan & $10 \mathrm{MY}$ & $11.81 \%$ & \multicolumn{2}{|c|}{$1.18 \%$} & \multicolumn{2}{|c|}{$3.08 \%$} & $0.31 \%$ \\
\hline Kopet-Dagh & $5 \mathrm{MY}$ & $8.52 \%$ & \multicolumn{2}{|c|}{$1.70 \%$} & \multicolumn{2}{|c|}{$1.52 \%$} & $0.30 \%$ \\
\hline Kuruk Tagh & $5 \mathrm{MY}$ & $6.55 \%$ & \multicolumn{2}{|c|}{$1.31 \%$} & \multicolumn{2}{|c|}{$1.05 \%$} & $0.21 \%$ \\
\hline
\end{tabular}

${ }^{a}$ Values above the dashed line are uncorrected pairwise distances and those below are uncorrected transversional distances. Abbreviations are MY $=$ million years and TV = transversions. 
Table 2

Comparative pairwise sequence divergences between species of amphibians and reptiles ${ }^{\mathrm{a}}$

\begin{tabular}{|c|c|c|c|c|}
\hline \multirow[b]{2}{*}{ Family } & \multirow[b]{2}{*}{ Genus } & \multicolumn{3}{|c|}{$\begin{array}{l}\text { Pairwise } \\
\text { Sequence }\end{array}$} \\
\hline & & Taxa Compared & Divergences & Reference \\
\hline Bufonidae & Bufo & $\begin{array}{l}\text { B. andrewsi and } \\
\text { B. gargarizans }\end{array}$ & $6.0-6.9 \%$ & Macey et al., 1998b \\
\hline Ranidae & Rana & $\begin{array}{l}\text { R. aurora, } \\
\text { R. cascadae and } \\
\text { R. muscosa }\end{array}$ & $7.0-8.4 \%$ & Macey et al., 2001 \\
\hline Salamandridae & Salamandra & $\begin{array}{l}\text { S. infraimmaculata } \\
\text { and S. salamandra }\end{array}$ & $7.4-7.5 \%$ & Weisrock et al., 2001 \\
\hline Agamidae & Laudakia & $\begin{array}{l}\text { L. caucasia and } \\
\text { L. erythrogastra }\end{array}$ & $4.2-5.3 \%$ & Macey et al., 1998a \\
\hline Anguidae & Elgaria & $\begin{array}{l}\text { E. kingii to the clade } \\
\text { containing } \\
\text { E. multicarinata, } \\
\text { E. panamintina and } \\
\text { E. paucicarinata }\end{array}$ & $4.8-5.9 \%$ & Macey et al., 1999a \\
\hline Gekkonidae & Teratoscincus & $\begin{array}{l}\text { T. przewalskii and } \\
\text { T. roborowskii }\end{array}$ & $6.5 \%$ & Macey et al., 1999b \\
\hline
\end{tabular}

${ }^{a}$ Sequence divergences are calculated for the same segment of mitochondrial DNA spanning from nadl to coxl. Bufonid frogs include only the first half of this segment (from nadl to nad2). 


\section{Figure legends}

Fig. 1. Map showing the distribution of the five Teratoscincus species examined in this study. One additional taxon, T. bedriagai, that occurs on the Iranian Plateau and Helmand Basin but not examined here is not shown. Major mountain ranges dividing species and discussed in the text are depicted.

Fig. 2. The single most parsimonious tree resulting from analysis of the 1733 (381 informative) aligned sites which is 1363 steps in length. Bootstrap values appear above branches and decay indices are presented below in bold. Geologic events hypothesized to have caused speciation are plotted on nodes. 
This work was performed under the auspices of the US Department of Energy's Office of Science, Biological and Environmental Research Program and by the University of California, Lawrence Livermore National Laboratory under Contract No. W-7405-Eng48, Lawrence Berkeley National Laboratory under contract No. DE-AC03-76SF00098 and Los Alamos National Laboratory under contract No. W-7405-ENG-36. 